This is a postprint of Fluid Phase Equilibria, 294, 2010, 31-38.

The original article can be found under:

http://www.sciencedirect.com/science/article/pii/S0378381210000695

\title{
COSMO-RS as a tool for property prediction of IL mixtures - a review
}

Michael Diedenhofen ${ }^{\mathrm{a},{ }^{*}}$, Andreas Klamt ${ }^{\mathrm{a}}$

${ }^{\text {a }}$ COSMOlogic GmbH \& Co. KG, Leverkusen, Germany

* Corresponding author. Tel.: +49(0)2171 731684; fax: +49(0)2171 731689

Email address: diedenhofen@cosmologic.de (M. Diedenhofen)

Keywords: COSMO, COSMO-RS, ionic liquids, activity coefficient, liquid-liquid equilibrium, vapor-liquid equilibrium, statistical thermodynamics, quantum chemistry

\begin{abstract}
In its first applications to ionic liquids the COSMO-RS method has shown to yield good qualitative and satisfying quantitative predictions for the activity coefficients of neutral compounds in ionic liquids and for binary mixtures of ionic liquids and neutral solvents. Since this success was achieved predictively, i.e. without any special parameterization, COSMO-RS since then has become a widely used and efficient tool for the prediction and screening of ionic liquid properties. In this article we give an overview of the various approaches and methodological differences used in this context by different groups.
\end{abstract}

\section{Introduction}

Ionic liquids (ILs) have attracted increasing attention during the past decades. The unique properties of ILs, such as wide electrochemical windows, extremely low vapor pressures, high solvating capacity and thermal stability, have led to interesting applications in many different areas [1-3]. The importance of ILs is reflected in the constantly growing number of experimental data for pure ILs or IL containing mixtures. The database of the IUPAC ionic liquids database project (IL Thermo) currently contains 22935 data points of properties for pure ionic liquids and 53614 data points for binary and ternary systems [4]. Although the 
number of experimental data is growing impressively, the application of predictive models for the estimation of thermodynamic properties is still an important issue. Such methods are crucial for the design of new ILs with specific properties and for property screening in the rapidly growing set of available or potentially available ILs. Especially fluid phase properties of IL containing mixtures, such as activity coefficients and solubilities are important for the design of separations processes, the choice of a reaction medium and many other applications. The models that have been applied to the prediction of these properties range from molecular dynamics (MD) using atomistic force fields [5, 6], over quantitative structure-property relationship (QSPR) models [7, 8] to classical thermodynamic models, such as NRTL, UNIQUAC, or UNIFAC [9-11]. Molecular dynamics simulations need appropriate forcefields that have to be specially developed for thermodynamic property prediction of ILs. The simulations have to be carried out carefully and may be time consuming, but give some insight into the molecular interactions in return. Group contribution methods have a limited applicability since the delocalization of the charges in ionic liquids require rather extended group definitions, and since the group interaction parameters for the large number of resulting groups have to be fitted to experimental data. Although the number of group interaction parameters of ILs has increased with the number of accessible experimental data [12], the space of systems directly predictable without additional parameterization is still very limited. This is a drawback that limits the applicability of UNIFAC to the design of new ILs. The quantum chemistry based COSMO-RS method, which is considered in this paper, has a small and general parameter set that does not have to be adjusted to ILs and therefore can be applied predictively to the full range of ILs. The first COSMO-RS application in this field was published in 2002 [13], and a lot of work has been done and published since then. The present paper summarizes the COSMO-RS applications on the thermodynamic data prediction of IL containing solutions. The focus is on the depiction and discussion of the techniques and results of the studies that have been done so far, rather than to present a complete literature review. In addition some new results are presented that extend the general survey.

\section{Theory}


This chapter presents a brief description of the theory needed for the understanding of the following discussion. A detailed description of the theory can be found in the references given.

\subsection{COSMO and COSMO-RS}

COSMO-RS (COSMO for real solvents) [14-17] is a quantum chemistry based statistical thermodynamics model for the prediction of thermodynamic properties of fluids and liquid mixtures.

The quantum chemical basis is a dielectric continuum model called COSMO (conductor-like screening model) [18]. In a COSMO calculation the solute is placed inside a molecular shaped cavity and the surrounding solvent is described by a continuum. Instead of using the exact dielectric boundary condition, COSMO in general applies a scaled-conductor boundary condition. Meanwhile COSMO is implemented in quantum chemical self-consistent field procedures in many quantum chemistry programs. For the purpose of COSMO-RS applications, COSMO calculations are performed in the un-scaled, i.e. perfect conductor. The solute electron density and geometry is thus converged to its energetically optimal state in a conductor, which is the reference state for the following COSMO-RS calculations. The resulting geometries, energies and surface screening charge densities $\sigma$ are stored in the socalled COSMO files.

COSMO-RS treats the solvent $S$ as an ensemble of pair-wise interacting surface segments. The interaction energies of the surface pairs are defined in terms of the screening charge densities $\sigma$ and $\sigma^{\prime}$ of the respective surface segments. For the COSMO-RS statistical thermodynamics it is sufficient to consider histograms of the screening charge densities, the so called $\sigma$-profiles $p^{X_{i}}(\sigma)$, which gives the relative amount of surface with polarity $\sigma$ for a molecule X. From the molecular $\sigma$-profiles the $\sigma$-profiles of pure or mixed solvents $\mathrm{S}$ can be easily derived as mole fraction weighted sum of the $\sigma$-profiles of its compounds in combination with a surface normalization:

$$
p_{S}(\sigma)=\frac{\sum_{i} x_{i} p^{X_{i}}(\sigma)}{\sum_{i} x_{i} A^{X_{i}}}
$$


Two energetic contributions of the most relevant molecular interaction modes, i.e.

electrostatics $\left(E_{\text {misfit }}\right)$ and hydrogen bonding $\left(E_{H B}\right)$ are described as functions of the screening charges of two interacting surface segments $\sigma$ and $\sigma^{\prime}$ or $\sigma_{\text {acceptor }}$ and $\sigma_{\text {donor }}$, if the segments belong to hydrogen bond donor or acceptor atom. The less specific van der Waals $\left(E_{v d W}\right)$ interactions are taken into account in a slightly more approximate way.

$$
\begin{aligned}
& E_{\text {misfit }}\left(\sigma, \sigma^{\prime}\right)=a_{e f f} \frac{\alpha^{\prime}}{2}\left(\sigma+\sigma^{\prime}\right)^{2} \\
& E_{H B}=a_{e f f} c_{H B} \min \left(0 ; \min \left(0 ; \sigma_{\text {donor }}+\sigma_{H B}\right) \max \left(0 ; \sigma_{\text {acceptor }}-\sigma_{H B}\right)\right) \\
& E_{v d W}=a_{e f f}\left(\tau_{v d W}+\tau_{v d W}^{\prime}\right)
\end{aligned}
$$

Eqs. 2-4 contain five adjustable parameters, an interaction parameter $\alpha^{\prime}$, the effective contact area $a_{\text {eff }}$, the hydrogen bond strength $c_{H B}$, the cutoff for hydrogen bonding $\sigma_{H B}$, and the element specific vdW interaction parameter $\tau_{v d W}{ }^{1}$.

Since the interactions of the solvent are described by $p_{S}(\sigma)$, the chemical potential of the surface segments can be calculated by solving a coupled set of non-linear equations.

$$
\mu_{S}(\sigma)=-R T \ln \left[\int p_{S}\left(\sigma^{\prime}\right) \exp \left(\frac{1}{R T}\left(a_{\text {eff }} \mu_{S}\left(\sigma^{\prime}\right)-E_{\text {misfit }}\left(\sigma, \sigma^{\prime}\right)-E_{H B}\left(\sigma, \sigma^{\prime}\right)\right)\right) d \sigma^{\prime}\right]
$$

$\mu_{S}(\sigma)$ is called $\sigma$-potential and it can be interpreted as the affinity of the solvent $S$ for surface of polarity $\sigma$. The vdW energy, which does not appear in eq. (5), can be added to the reference energy in solution. Finally, the pseudo-chemical potential [19] of compound $X_{i}$ in the system $S$ can be calculated by integration of $\mu_{S}(\sigma)$ over the surface of the compound.

$$
\mu_{S}^{X}=\mu_{C, S}^{X}+\int p^{X_{i}}(\sigma) \mu_{S}(\sigma) d \sigma
$$

In order to take into account size and shape differences of the molecules in the system an additional area and volume depending combinatorial term $\mu_{C, S}^{X_{i}}$, is added in close analogy to combinatorial terms routinely used chemical engineering models. The required molecular surface areas and volumes are taken from the COSMO cavities.

\footnotetext{
${ }^{1}$ Typical parameters are: $a_{\text {eff }}=6.25 \AA^{2} ; \alpha^{\prime}=5950 \mathrm{~kJ} / \mathrm{mol} / \AA^{2} ; c_{H B}=36.7 \mathrm{~kJ} / \mathrm{mol} / \AA^{2} ; \sigma_{H B}=0.085 \mathrm{e} / \AA^{2} ; \tau_{v d W}$ [kJ/mol/ $\left.\AA^{2}\right]$ : H 0.0361, C 0.0401, N 0.0181, O 0.0189, F 0.0265, S 0.0510, Cl 0.0514, Br 0.0550, I 0.0580 [16].
} 
With eq. 6 we are able to calculate the chemical potential of all compounds of an arbitrary mixture at a given temperature and a wide variety of thermodynamic properties can be derived, e.g. the activity coefficient,

$$
\gamma_{S}^{X_{i}}=\exp \left\{\frac{\mu_{S}^{X_{i}}-\mu_{X_{i}}^{X_{i}}}{R T}\right\},
$$

where $\mu_{X_{i}}^{X_{i}}$ denotes the potential of compound $X_{i}$ in the reference state of the pure compound.

\subsection{Computational details}

The quantum chemical $\mathrm{COSMO}^{2}$ calculations were performed on the density functional theory (DFT) level, utilizing the BP functional [20-22] with RI (resolution of identity) approximation and a triple- $\zeta$ valence polarized basis set (TZVP) [23, 24]. All structures were fully optimized. The quantum chemical calculations have to be performed only once for each molecule. The results of the COSMO calculation are stored in the so-called COSMO files, which are collected in a database. All calculations were performed with the TURBOMOLE program package [25].

COSMO-RS calculations were performed using the COSMOtherm program, which provides an efficient and flexible implementation of the COSMO-RS method [26]. The BP_TZVP_C12_0108 parameterization has been used. As already shown in the first COSMOtherm IL applications [13, 27], ionic liquids can be treated predictively, without special adaptations of the theory, the element specific COSMO-radii used in the DFTCOSMO calculations, or the parameterizations. Indeed, no ionic compounds at all are included in the COSMOtherm parameterization data set.

\section{Ionic Liquids in the COSMO-RS framework}

\subsection{Conformer treatment}

Most of the more complex molecules have more than one relevant geometric conformation. Although not a special IL topic, the treatment of conformers in COSMO-RS calculations of IL solutions has been discussed extensively [28-34]. The population of the conformers depends

\footnotetext{
${ }^{2}$ The following element specific radii $[\AA]$ have been used in the cavity construction: $\mathrm{H}: 1.3, \mathrm{C}: 2.0, \mathrm{~N}: 1.83, \mathrm{O}$ : 1.72, F: 1.72, P: 2.106, S: 2.16, Cl: 2.05, I: 2.32.
} 
on its surrounding and the energetic order, with respect to the free energy in solution, may differ between polar and non-polar solvent. The minimum conformation of a molecule $X$ in the gas phase, for instance, is most likely also the minimum conformation in non-polar solvents like hexane, but not necessarily in water. Especially polar molecule with hydrogen bond capacity show strong effects. The COSMO-RS theory allows for a consistent conformer treatment. The $\sigma$-profile of a compound can be represented by a set of conformer $\sigma$-potentials, which is weighted according to the Boltzmann distribution between conformers of different free energies. Since the conformer population changes the free energy of the species in the mixture, the conformer weighting has to be iterated self-consistently together with eq. 5 [17]. Another approach used by Banerjee et al. is a kind of $0^{\text {th }}$ order correction of the $\sigma$-profile, where the weight factors of the individual conformer $\sigma$-profiles are kept fixed during the iterative computation of the $\sigma$-potential (eq. 5) [29, 30].

The set of relevant conformer $\sigma$-profiles has to be explored by separate COSMO calculations of the conformers of interest. Since the number of possible conformations increases exponentially with the number of rotatable bonds, a procedure for the selection of the important conformers is crucial. An obvious criterion is the COSMO energy, which can be used as a $0^{\text {th }}$ order approximation to the a priori unknown free energy in solution.

Energetically high lying conformers with an unfavorable COSMO energy need a substantial correction by the chemical potential in solution in order to contribute significantly to the Boltzmann statistics. Another suitable criterion is the similarity of the $\sigma$-profiles, which can be quantified by the sigma match similarity (SMS) [35]. Conformers with similar $\sigma$-profile and energy should influence the properties in the same way. Therefore, conformational changes of an non-polar side chain are not important, whereas changes of the conformation of polar moieties, e.g. hydrogen bonds, that are leading to a notably different $\sigma$-profile, have to be taken into account. A generally usable conformer set should at least contain the energetically favorable conformations for both limits, polar and non-polar solvents. The conformers for the molecules used in this study have been created and selected with a partly automated procedure using the COSMO energies and SMS as selection criteria.

\subsection{Molecular description of the ILs}

In contrast to a classical solvent, an ionic liquid can be described either as a single compound or as a mixture of ions. While for many experimental issues these two descriptions just affect the definition of the mole fraction, they reflect a different chemistry on the atomistic scale. 
The ions in an ionic liquid can form an ion-pair or exist as distinct ions. Between these two limits cluster formation or other types of aggregation, which dependent on the composition and temperature of the mixture, are conceivable.

Fig. 1 depicts the three different descriptions that have been used in COSMO-RS calculations so far.

\section{<figure 1>}

a) The meta-file approach: the ions are treated separately in the quantum chemical COSMO calculations, but in the COSMO-RS calculation the IL is described as the sum of the $\sigma$-profiles, areas and volumes of the ions. Technically, the results of the distinct COSMO calculations of the ions are combined into one file, the so-called meta-file.

b) The ion-pair approach: the COSMO optimized structure of the ion-pair is used. Since IL ions are usually weakly coordinating, this mostly requires a large set of conformations of the ion-pairs.

c) The electroneutral mixture: the distinct ions, which have been treated separately in the COSMO calculations, are used as an electroneutral mixture in the COSMO-RS calculations, i.e. the mole fraction ratio of the ions must reflect the stoichiometry of the IL at any composition of the mixture. As a consequence, the mole fraction used in the calculations differs from the mole fraction normally used in experiments, where the IL is treated as one compound. For a mixture of a 1:1 IL like $\left[\mathrm{C}_{4} \mathrm{mim}\right][\mathrm{Cl}]$ and one solute, for instance, the mole fraction used in experiments depends on the binary system, whereas the mole fraction used in the COSMO-RS calculation depends on the ternary system. Therefore, properties that depend on the mole fraction definition, such as activity coefficients and Henry's law constants have to be converted whenever used together with the other mole fraction definition. The activity coefficient of a solute $X$ in the ternary mixture $\gamma_{X}^{\text {tern }}\left(1: 1 \mathrm{IL}\right.$, cation + anion + solute, $\left.x_{\text {anion }}^{\text {tern }}=x_{\text {cation }}^{\text {tern }}=x_{\text {ion }}^{\text {tern }}\right)$ can be converted into the binary definition $\gamma_{X}^{b i n}$ using the relation

$$
\gamma_{X}^{\text {bin }}=\gamma_{X}^{\text {tern }}\left(x_{X}^{\text {tern }}+x_{i o n}^{\text {tern }}\right)
$$

thus leading to a scaling factor of 0.5 for the activity coefficient at infinite dilution of the solute $X$.

The advantage of the meta-file approach and the electroneutral mixture is the use of distinct ions. By using a database of COSMO files of anions and cations, a huge number of ILs is 
accessible without additional quantum chemical calculations, which is especially important for IL screening purposes. Furthermore, the conformational space of the ions is by far smaller and easier to access than the conformational space of the ion-pairs. Palomar et al. used the meta-file and the ion-pair approach for a $\sigma$-profile based QSPR model for the prediction of molar volumes [36, 37] and found a better correlation for the ion-pair model. Based on a comparison of the $\sigma$-profiles, the authors concluded that the counterion interactions in the ion-pair model leads to a weaker hydrogen bond capacity compared to the meta-file model [36]. Another successful application of the ion-pair model is the prediction of the enthalpies of vaporization of $\left[\mathrm{C}_{2} \mathrm{mim}\right]\left[\mathrm{EtSO}_{4}\right],\left[\mathrm{C}_{4} \mathrm{mim}\right][\mathrm{dca}]$ and the $\left[\mathrm{C}_{\mathrm{x}} \mathrm{mim}\right]\left[\mathrm{NTf}_{2}\right](\mathrm{x}=2,4,6,8)$ series. The ILs were described as electroneutral mixtures and as ion-pairs [38]. Both approaches exhibited good agreement with the experimental values. Although just one conformer was used for the ion-pair, the results were surprisingly good. Nevertheless, the ion-pair represents just a snapshot of the cation-anion interactions in the liquid and the consideration of the whole set of important conformations, taking into account all interaction modes, is not feasible. Banerjee et al. used the ion-pair and the meta-file approach for the prediction of VLE and LLE data [30]. In both cases the meta-file approach was superior to the ion-pair model with drastic improvement for the LLE predictions. Besides the mole fraction definition discussed above, the meta file and the electroneutral mixture approach differ in two aspects: the combinatorial contribution to the chemical potentials and the conformer treatment. Since the combinatorial term depends on the mole fractions, molecular areas and volumes of the species it leads to different contributions for two approaches. The self-consistent treatment within the meta file approach is limited, because all combinations of anion and cation conformers need to be taken into account. Therefore, we currently use the electroneutral mixture as the most flexible description of an IL. The interactions modes of the COSMO-RS model can account for the interactions in weak ion-pairs or higher aggregations as well as for the separated ions, which should cover a big part of the range of interactions in the IL mixtures.

An example of a liquid-liquid phase equilibrium calculated with the different representations of the IL is given in fig. 2.

\section{<figure 2>}

The results show a substantial overestimation for the LLE curve calculated with the meta-file approach. In this calculation only one conformer per molecule has been used. 
Opposed to the meta-file result, the LLE curves calculated with the electroneutral mixture approach, reveal a better agreement with the experimental values. Only a moderate difference between the curve calculated with one conformer or a set of conformers is found.

The structures of the minimum (with respect to the COSMO energy) conformers are shown in fig. 3 .

\section{<figure 3>}

Since the screening charge density $\sigma$ shown in fig 3 is the response of the conductor, the values are opposed to the molecular polarity. The hydroxyl oxygen of 1-butanol, for instance, shows a positive screening charge colored in red. The $\left[\mathrm{NTf}_{2}\right]$ anion exhibits mainly positive $\sigma$ values (yellow/green), while the $\left[\mathrm{C}_{2} \mathrm{mim}\right]$ cation shows mainly negative screening charge density (blue/green). Compared to 1-butanol, the ions exhibit moderate $\sigma$ values. This can be seen more clearly from the $\sigma$-profiles plotted in fig4.

\section{<figure 4>}

The $\sigma$-profile of 1-butanol reveals as wider range than the $\sigma$-profiles of the ions. On the left hand side of the histogram, i.e. in the hydrogen bond donor region $\left(\sigma<-\sigma_{H B} ; \sigma_{H B} \approx 0.009\right.$ $\mathrm{e} / \AA^{2}$ ), the maximum $\sigma$ value of 1-butanol is slightly more polar than that of $\left[\mathrm{C}_{2} \mathrm{mim}\right]$. In the hydrogen bond acceptor region $\left(\sigma>\sigma_{H B}\right)$ 1-butanol shows surface with much higher $\sigma$ values than the maximum $\sigma$ value of $\left[\mathrm{NTf}_{2}\right]$-ion, originating from the hydroxyl oxygen. This finding is typical for ILs. Normally IL ions do not exhibit very polar hot spots like alcohols or water, which surely is one reason for the low melting point of these substances.

\section{Applications}

\subsection{Activity coefficients at infinite dilution}

Activity coefficients at infinite dilution are interesting in several respects, especially for the preliminary selection of solvents for extractive distillation and liquid-liquid extraction. In the first COSMO-RS application to the prediction of activity coefficients at infinite dilution from 2003, a set of 38 solutes (hydrocarbons, alcohols and polar organics) in $\left[\mathrm{C}_{2} \mathrm{mim}\right]\left[\mathrm{NTf}_{2}\right]$, $\left[\mathrm{C}_{2} \mathrm{C}_{1} \mathrm{mim}\right]\left[\mathrm{NTf}_{2}\right]$ and $\left[\mathrm{C}_{1} \mathrm{C}_{4}\right.$ py] $\left[\mathrm{BF}_{4}\right]$ has been investigated [27]. The predictions, obtained with the electroneutral mixture approach, exhibit the same accuracy that is observed for normal organic solvents. The largest deviations from the experimental values has been found for $\left[\mathrm{C}_{1} \mathrm{C}_{4} \mathrm{py}\right]\left[\mathrm{BF}_{4}\right]$ with a root mean square deviation of $0.52 \mathrm{ln}$ units, mainly due to the 
underestimation for alkanes, alkenes and polar organic compounds. Banerjee and Khanna used a special COSMO-RS implementation, originally fitted for the LLE prediction of neutral compounds [29], for the prediction of activity coefficients at infinite dilution in ILs based on the of the phosphonium cation $\left[\mathrm{P}_{6,6,6,14}\right]$ and the anions $\left[\left(\mathrm{C}_{2} \mathrm{~F}_{5}\right)_{3} \mathrm{PF}_{3}\right],[\mathrm{Cl}],\left[\mathrm{BF}_{4}\right]$ and $\left[\mathrm{NTf}_{2}\right]$ [39]. After a first benchmark on the $\left[\mathrm{P}_{6,6,6,14}\right]\left[\left(\mathrm{C}_{2} \mathrm{~F}_{5}\right)_{3} \mathrm{PF}_{3}\right]$ system, that yielded an average absolute deviation (AAD) of the $\gamma^{\infty}$ values of about $11.5 \%$, the authors predicted the activity coefficients of hydrocarbons and alcohols in the other three ILs. The reported AADs for $\left[\mathrm{P}_{6,6,6,14}\right][\mathrm{Cl}],\left[\mathrm{P}_{6,6,6,14}\right]\left[\mathrm{BF}_{4}\right]$ and $\left[\mathrm{P}_{6,6,6,14}\right]\left[\mathrm{NTf}_{2}\right]$ are $9 \%, 8 \%$ and $16 \%$, respectively. In contrast to these studies, Kato and Gmehling reported unsatisfying results for the activity coefficient at infinite dilution of hydrocarbons, alcohols and water in $\left[\mathrm{C}_{\mathrm{x}} \mathrm{mim}\right]\left[\mathrm{NTf}_{2}\right](\mathrm{x}=$ $1,2,4,6,8)$ and $\left[\mathrm{C}_{1} \mathrm{C}_{4} \mathrm{py}\right]\left[\mathrm{NTf}_{2}\right]$ with relative deviations between the experimental and the predicted results of more than 100\% [11]. They used the COSMO-RS(OL) implementation and the meta-file approach together with DFT screening charges. However, the structures of the ions have been optimized on the insufficient semi-empirical (AM1) gas phase level only, which might be one source of error. Another reason may be the parameterization data set of the COSMO-RS(Ol) re-implementation of COSMO-RS which is much more biased towards less polar compounds than the parameterization data sets used in the original COSMO-RS parameterizations.

\subsection{Gas solubilities and Henry's law constants}

The solubility of gases in ILs is important for many applications, e.g. the choice of an IL as medium for reactions that involve gases or the extraction of a component from a gas mixture. Because of the global warming problem, the $\mathrm{CO}_{2}$ capture capability of ILs has become of special interest for the $\mathrm{CO}_{2}$ emission control and utilization. In a recent COSMO-RS screening study of Henry's constants of $\mathrm{CO}_{2}$ in $408 \mathrm{ILs}$, Zhang et al. reported an improved $\mathrm{CO}_{2}$ capture capability for ILs that are based on the $\left[\left(\mathrm{C}_{2} \mathrm{~F}_{5}\right)_{3} \mathrm{PF}_{3}\right]$ anion [40]. A new model that allows for a good quantitative prediction of $\mathrm{CO}_{2}$ solubilities in ILs has been proposed by Maiti [41]. The model is combination of COSMO-RS with an equation of state (EoS) and needs two additional, solvent and pressure independent, fit parameters. In a study of $\mathrm{Ab}$ Manan et al. [42] the predictive capability of COSMO-RS with respect to the solubility of 15 gases in 27 ILs has been evaluated carefully. The authors report that COSMO-RS is qualitatively capable of predicting gas solubilities in ionic liquids with a relative absolute deviation of $36.9 \%$. 


\subsection{Liquid-liquid equilibria (LLE)}

The thermodynamic requirement for an equilibrium of two coexisting phases can be expressed by the equality of the chemical potentials of all species $i$ in the phases I and II.

$$
\mu_{i}^{I}=\mu_{i}^{I I}
$$

The $\mu_{i}$ can be calculated from the pseudo chemical potential defined in eq. 6 .

$$
\mu_{i}=\mu_{S}^{X_{i}}+R T \ln \left(x_{i}\right)
$$

In the electroneutral mixture approach the chemical potential of the IL is defined as the sum of the chemical potentials of the ions weighted by the stoichiometry.

The prediction of the LLEs of the $\left[\mathrm{C}_{4} \mathrm{mim}\right]\left[\mathrm{PF}_{6}\right]-$ alcohol systems by Marsh et. al. in 2002 was the first published work on the use of COSMO-RS for IL containing mixtures [13]. The calculations were done using the meta-file approach, whereas the following, more extended, examinations of the group on the $\left[\mathrm{C}_{\mathrm{x}} \mathrm{mim}\right]\left[\mathrm{PF}_{6}\right]-1-$ alcohol $(\mathrm{x}=4-8)$ systems used the electroneutral ion mixtures $[31,43]$. The use of the electroneutral ion mixtures improved the results markedly leading to a reasonable description of the composition dependence and a remarkable good prediction of the UCST. Sahandzhieva et al. used their new measurements of the $\left[\mathrm{C}_{4} \mathrm{mim}\right]\left[\mathrm{PF}_{6}\right]-$ alcohol LLEs for another COSMO-RS evaluation [44]. They discuss the influence of different versions of COSMOtherm, which mainly differ in the parameterization details. The official parameterizations C1.2.01.03 and C2.1.0104 yield quite similar results while the C1.2.05.02 parameterization, which was only a developers version, show markedly different results, closer to the results of Marsh et al., that have been obtained with an older parameterization from 2001.

In 2006 two studies on the LLEs of $\left[\mathrm{C}_{\mathrm{x}} \mathrm{mim}\right]\left[\mathrm{MeSO}_{4}\right](\mathrm{x}=1,4)$ with several ethers, ketones [45] and hydrocarbons [46] were published by Domańska et al.. The equimolar ion mixture was used throughout the studies. For the ether and ketone systems the predicted curve lines are similar to the experiment, while the quantitative values show significant disagreement with the experiment. The order of the predicted curves for the various solvents corresponds to 
the experimental findings in most of the cases. The predictions for the hydrocarbon LLEs reveal a similar picture.

Freire et al. conducted two elaborated evaluation studies on the prediction of LLEs of ILalcohol [32] and IL-water systems [33]. The ILs in the calculations of these studies were described as electroneutral mixtures of the ions. For the IL-alcohol study a set of imidazolium and pyridinium based ILs was used, while the IL-water study contained additional pyrrolidinium based ILs. The anions were $\left[\mathrm{BF}_{4}\right],\left[\mathrm{PF}_{6}\right]$ and $\left[\mathrm{NTf}_{2}\right]$ in both cases. In case of the IL-alcohol LLEs the authors draw the conclusion that, in spite of some shortcomings, COSMO-RS provides reasonable qualitative accordance with the experimental results, whereas the IL-water systems can be described much better. The model gives satisfactory $a$ priori qualitative predictions and the quantitative description is improved compared to the binary systems with alcohols, alkanes [46] and ketones [45]. Some systems, such as the LLEs of water with $\left[\mathrm{C}_{3} \mathrm{mim}\right]\left[\mathrm{NTf}_{2}\right]$ or $\left[\mathrm{C}_{3} \mathrm{C}_{1} \mathrm{pyr}\right]\left[\mathrm{NTf}_{2}\right]$, can be predicted in good quantitative accordance with the experiment. Certain effects, e.g. the influence of the cation alkyl chain length of $\left[\mathrm{C}_{\mathrm{x}} \mathrm{mim}\right]$ imidazolium ions on the mutual solubilities can be predicted for IL-alcohol and IL-water systems, although the behavior of the IL-alcohol and the IL-water systems follow opposite trends. Other trends, such as the effect of a methyl group in 2-position of the imidazolium ring can be predicted correctly for the $\left[\mathrm{C}_{4} \mathrm{mim}\right]\left[\mathrm{PF}_{6}\right] /\left[\mathrm{C}_{4} \mathrm{C}_{1} \mathrm{mim}\right]\left[\mathrm{PF}_{6}\right]$-water systems but not for $\left.\left[\mathrm{C}_{6} \mathrm{C}_{1} \mathrm{mim}\right]\left[\mathrm{NTf}_{2}\right] /\left[\mathrm{C}_{6} \operatorname{mim}\right] \mathrm{NTf}_{2}\right]$ with 1-hexanol. Other studies on ILwater systems of the same group revealed similar results [47, 48].

It should be noted, that small effects, e.g. the difference in the mutual solubility of 1-propanol and 2-propanol in $\left[\mathrm{C}_{4} \mathrm{mim}\right]\left[\mathrm{BF}_{4}\right]$, where the experimental line shape is quite similar and the difference of the UCST of the LLE curve is below $5 \mathrm{~K}$, are clearly beyond the scope of the COSMO-RS model.

Banerjee et al. used the meta-file approach together with an implementation of COSMO-RS that has been refitted for LLE predictions of neutral compounds [30, 29].

The root mean square deviation of the phase compositions of 36 ternary LLE data sets of ILs (imidazolium, pyridinium, sulfates, $\left[\mathrm{BF}_{4}\right],\left[\mathrm{PF}_{6}\right]$ and $[\mathrm{Cl}]$ ) with alcohols, ethers, alkanes and aromatic compounds is $\sim 9 \%$, which indicates a good quantitative agreement with the experimental data. A check of the ion-pair approach on the same data set showed a substantial reduction of the accuracy. 
An interesting test case for the a priory prediction is the LLE of the mutually immiscible ILs $\left[\mathrm{C}_{2} \mathrm{py}\right]\left[\mathrm{NTf}_{2}\right]+\left[\mathrm{P}_{6,6,6,14}\right]\left[\mathrm{NTf}_{2}\right]$ and $\left[\mathrm{C}_{2} \mathrm{mim}\right]\left[\mathrm{NTf}_{2}\right]+\left[\mathrm{P}_{6,6,6,14}\right]\left[\mathrm{NTf}_{2}\right]$ measured by Arce et al. [49]. A comparison of calculated (electroneutral mixture) and experimental data is given in fig. 5 .

\section{<figure 5>}

The shape of the calculated LLE curves, as well as the cation effect $\left(\left[\mathrm{C}_{2} \mathrm{mim}\right]\right.$ versus $\left[\mathrm{C}_{2}\right.$ py $\left.]\right)$ on the mutual solubilities, is predicted correctly. Although no quantitative accordance with the experimental values could be achieved, the results are remarkable for a system that exhibit IL-IL interaction only.

In conclusion, COSMO-RS LLE calculations are able to predict the qualitative behavior of LLEs in most cases, and that some system can even be predicted quantitatively. The immiscibility of the IL mixtures could be detected in nearly all of the cases. This is remarkable for a model that only uses information from a quantum chemical calculations and that has not been specially adjusted for IL containing mixtures.

\subsection{Vapor-liquid equilibria VLE}

Banerjee et al. used a COSMO-RS variant, that has been fitted to the VLE data of neutral systems, for the VLE prediction of a set of $13 \mathrm{IL}$ systems $\left(\left[\mathrm{C}_{\mathrm{x}} \mathrm{mim}\right]\left[\mathrm{NTf}_{2}\right](\mathrm{x}=1,2,4)\right.$, $\left.\left[\mathrm{C}_{1} \mathrm{mim}\right]\left[\mathrm{Me}_{2} \mathrm{PO}_{4}\right],\left[\mathrm{C}_{2} \mathrm{mim}\right]\left[\mathrm{EtSO}_{4}\right]\right)$ with benzene, cyclohexane, acetone, 2-propanol, water and tetrahydrofuran [50]. The authors used the ion-pair model and achieved a good agreement with the experimental values with a root mean square deviation of the vapor pressure of about $6 \%$. In a rework the use of the meta-file approach on the same data set reduces the root mean square deviation to $3.7 \%$ [30].

The COSMO-RS predictions of the VLEs of $\left[\mathrm{C}_{\mathrm{x}} \mathrm{mim}\right]\left[\mathrm{NTf}_{2}\right](\mathrm{x}=2,4,6),\left[\mathrm{C}_{4} \mathrm{mim}\right]\left[\mathrm{OctSO}_{4}\right]$ with ethanol, propanol, 2-propanol and methanol [32] and $\left[\mathrm{C}_{\mathrm{x}} \operatorname{mim}\right]\left[\mathrm{NTf}_{2}\right](\mathrm{x}=2,4)$, $\left[\mathrm{C}_{4} \mathrm{mim}\right][\mathrm{I}],\left[\mathrm{C}_{4} \mathrm{mim}\right]\left[\mathrm{BF}_{4}\right],\left[\mathrm{C}_{\mathrm{x}} \mathrm{mim}\right]\left[\mathrm{PF}_{6}\right](\mathrm{x}=4,8),\left[\mathrm{C}_{1} \mathrm{mim}\right]\left[\mathrm{Me}_{2} \mathrm{PO}_{4}\right],\left[\mathrm{C}_{2} \mathrm{mim}\right]\left[\mathrm{EtSO}_{4}\right]$ with water [33] have been reported by Freire et al.. The results, obtained with the electroneutral ion 
mixture, are superior to the LLE predictions on similar systems reported in the same articles. For the IL-alcohol VLEs, the correct temperature dependence of the liquid phase non-ideality, and the positive deviation from Raoult's law with decreasing alkyl chain length, can be described adequately. An overestimation of the positive deviation of Raoult's law appears for very short chain alcohols, such as methanol. In case of the IL-water VLEs better agreement is reported for the hydrophobic anion $\left[\mathrm{NTf}_{2}\right]$ than for the more polar anions. The temperature dependence of the pressure can be described qualitatively.

Two new examples for the COSMO-RS VLE prediction, one for hydrophobic fluorinated alkanes $+\left[\mathrm{C}_{4} \mathrm{mim}\right]\left[\mathrm{PF}_{6}\right][51]$, and another for the polar ammonia $+\left[\mathrm{C}_{6} \mathrm{mim}\right][\mathrm{Cl}][52]$, measured by Yokozeki and Shiflett are given in fig. 6, 7 and 8 .

\section{<figure 6>}

The partial pressures of the compounds $i$ have been calculated using the relation

$$
p_{i}=\gamma_{S}^{X_{i}} p_{i}^{o} x_{i}
$$

where $p_{i}^{0}$ denotes the pure compound vapor pressure of the compound $i$. For ammonia an extended Antoine equation from ref. [53] has been used. The pure compound vapor pressures of the fluorinated alkanes have been taken from the experimental paper [51] (Antoine equation). The partial pressure of the ILs in the binary mixtures has been assumed to be zero.

\section{<figure 7> \\ <figure 8>}

The COSMO-RS calculations for the fluoroalkane- $\left[\mathrm{C}_{4} \mathrm{mim}\right]\left[\mathrm{PF}_{6}\right]$ VLEs reveal a good agreement with the experimental values for both temperatures (fig. 7 and 8). Substantial deviations can be found for trifluoromethane at mole fractions above 0.1 only. The temperature effect on the pressure of pentafluoroethane, which is opposite to the behavior of the fluoromethanes, can be predicted correctly. As can be seen in fig. 6, for all temperatures and compositions the calculated values for the polar $\mathrm{NH}_{3}-\left[\mathrm{C}_{6} \mathrm{mim}\right][\mathrm{Cl}]$ mixtures are in good quantitative accordance with the experimental values.

\subsection{Ionic liquid screening and tailoring}


A consequent thermodynamic optimization of ILs as entrainers in the distillative separation of tetrahydrofurane / water and methylcyclohexane / toluene based on COSMO-RS predictions has been presented by Jork et al. [28]. After an evaluation of the method, which proved the capability of the model, the activity coefficients at infinite dilution of the compounds in the ILs have been used for the IL screening. A similar strategy has been used for the 1-hexene / hexane separation and the extraction of drugs from urine by Lei et al. [34, 54] and for the thiophene extraction by Kumar et al. [55]. The influence of different ILs on the an enzymatic glycerolysis reaction has been studied by Guo et al. [56]. Maiti et. al. [57] used predicted solubilities for the solvent screening for the hard to dissolve 1,3,5-triamino-2,4,6trinitrobenzene crystal. For a small evaluation set of imidazolium cations with $[\mathrm{F}],[\mathrm{Cl}]$ and $[\mathrm{Br}]$ as anion, excellent agreement with the experimental data has been obtained.

As already mentioned, the advantage of the use of separate ion COSMO files in a COSMORS calculation, is the huge number of ion combinations that can be accessed from a small number of ion COSMO files. Thus, in a preliminary screening procedure one can start with all possible ion combinations. For separations, for instance, the activity coefficients of a solute in all ion combinations can be calculated using an automated procedure. Since the COSMO-RS calculations are not time consuming, a set of several thousand ion combinations can be processed over night on a single modern CPU. At the end the most promising IL can be picked from the answer set. Ion combinations not already known as ILs can at least provide information about the structural characteristics that seems to be important.

\section{Conclusions}

The direct derivation of the molecular interactions from quantum chemical calculations makes COSMO-RS an especially efficient tool for the prediction of the properties of ionic liquids, and for the thermodynamic properties of solutes in such systems, because alternative approaches as force fields and group contribution methods have major problems to describe the complicated and often very delocalized ionic charges of such systems. Therefore, COSMO-RS is meanwhile widely used for ionic liquid property prediction and screening in academic research and in industry, and apart from some reported problems the general conclusion of most papers on this topic is that COSMO-RS does yield reliable qualitative and acceptable quantitative results, which are at least useful for a pre-selection of suitable ionic liquid candidates for certain tasks. Despite of various re-implementations and 
parameterizations of COSMO-RS, the largest methodological difference in the application of COSMO-RS to ionic liquids arises from the mode of representation of the ionic liquid in the COSMO-RS algorithm. The three relevant modes are the representation as electroneutral mixture of anions and cations, the representation as ion-pairs, and the representation as separate, but virtually connected super molecules, the so-called meta-file approach. From a synopsis of the available literature and from many own calculations we conclude that the electroneutral mixture representation, which we consider as the physically most plausible representation in the liquid phase of ionic liquids, in most cases does lead to the most accurate predictions.

\section{Abbreviations}

\section{Cations}

[ $\mathrm{C}_{\mathrm{x}} \mathrm{mim}$ 1-alkyl-3-methylimidazolium

$\left[\mathrm{C}_{\mathrm{x}} \mathrm{C}_{1}\right.$ mim $]$ 1-alkyl-2,3-dimethylimidazolium

[C $\left.\mathrm{C}_{\mathrm{x}} \mathrm{py}\right] \quad$ 1-alkylpyridinium

$\left[\mathrm{C}_{1} \mathrm{C}_{4} \mathrm{py}\right]$ 4-methyl-N-butylpyridinium

[ $\mathrm{C}_{3} \mathrm{C}_{1}$ pyr $]$ 1-methyl-1-propylpyrrolidinium

$\left[\mathrm{P}_{6,6,6,14}\right] \quad$ trihexyl-tetradecylphosphonium

alkyl methyl $(x=1)$, ethyl $(x=2)$, propyl $(x=3)$, etc.

\section{Anions}

[F] fluoride

[Cl] chloride

[Br] bromide

[I] iodide

[ $\left.\mathrm{NTf}_{2}\right]$ bis(trifluoromethylsulfonyl)amide

$\left[\mathrm{MeSO}_{4}\right]$ methylsulfate

$\left[\mathrm{EtSO}_{4}\right] \quad$ ethylsulfate

[OctSO $\left.{ }_{4}\right]$ octylsulfate

$\left[\mathrm{Me}_{2} \mathrm{PO}_{4}\right]$ dimethylphosphate

$\left[\left(\mathrm{C}_{2} \mathrm{~F}_{5}\right)_{3} \mathrm{PF}_{3}\right]$ tris(pentafuoroethyl)trifluorophosphate

[dca] dicyanamide 
$\left[\mathrm{PF}_{6}\right] \quad$ hexafluorophosphate

\section{List of symbols}

$\begin{array}{ll}a_{e f f} & \text { effective contact area } \\ c_{H B} & \text { hydrogen bond strength parameter } \\ e & \text { elementary charge } \\ E_{\text {misfit }} & \text { electrostatic misfit energy } \\ E_{H B} & \text { hydrogen bond energy } \\ E_{v d W} & \text { van der Waals energy } \\ p_{i} & \text { partial pressure of compound } i \\ p_{i}^{o} & \text { pure compound vapor pressure of compound } i \\ P_{S}(\sigma) & \sigma \text {-profile of a solvent } \\ P^{X}(\sigma) & \sigma \text {-profile of a compound } \\ \mathrm{R} & \text { ideal gas constant } \\ \mathrm{T} & \text { temperature } \\ x & \text { mole fraction }\end{array}$

Greek symbols

$\mu_{S}^{X} \quad$ pseudo chemical potential of a solute $X$ in solvent $S$

$\mu_{C, S}^{X} \quad$ combinatorial contribution to the chemical potential of the solute $X$ in the solvent $S$

$\gamma_{S}^{X} \quad$ activity coefficient of a solute $X$ in solvent $S$

$\mu_{X}^{X} \quad$ pseudo chemical potential of a solute in itself

$\mu_{i} \quad$ chemical potential of compound $i$

$\sigma \quad$ screening charge density

$\alpha^{\prime} \quad$ electrostatic misfit parameter

$\sigma_{\text {donor }} \quad$ screening charge density on hydrogen bond donor segment

$\sigma_{\text {acceptor }} \quad$ screening charge density on hydrogen bond acceptor segment

$\sigma_{H B} \quad$ hydrogen bonding cutoff screening charge density

$\tau_{v d W} \quad$ element specific

$\mu_{S}(\sigma) \quad \sigma$-potential

\section{References}


[1] F. Endres, S.Z. El Abedin, Phys. Chem. Chem. Phys. 8 (2006) 2101-2116.

[2] T. Welton, Chem. Rev. 99 (1999) 2071-2083.

[3] A. Heintz, J. Chem. Thermodynamics 37 (2005) 525-535.

[4] http://ilthermo.boulder.nist.gov

[5] C.G. Hanke, S.L. Price, R.M. Lynden-Bell, Mol. Phys. (2001) 99 801-809.

[6] J.K. Shah, J.F. Brennecke, E.J. Maginn, Green. Chem. 4 (2002) 112-118.

[7] L. Spunger, M. Clark, W.E. Acree Jr., M.H. Abraham, J. Chem. Inf. Model 47 (2007) 1123-1129.

[8] M.H. Abraham, W.E. Acree Jr., Green Chem. 8 (2006) 906-915.

[9] R.S. Santiago, G.R. Santos, M. Aznar, Fluid Phase Equilibria 287 (2009) 54-61.

[10] E.I. Alevizou, G.D. Pappa, E.C. Voutsas, Fluid Phase Equilibria 284 (2009) 99-105.

[11] R. Kato, J. Gmehling, J. Chem. Thermodyn. 37 (2005) 603-619.

[12] S. Nebig, R. Bölts, J. Gmehling, Fluid Phase Equilibria 258 (2007) 168-178.

[13] K. N. Marsh, A. Deev, A. C-T. Wu, E. Tran, A. Klamt, Korean J. Chem. Eng. 19 (2002) 357-362.

[14] A. Klamt, J. Phys. Chem. 99 (1995) 2224-2235.

[15] A. Klamt, V. Jonas, T. Bürger, J.C.W. Lohrenz, J. Phys. Chem. A 102 (1998) 5074-5085.

[16] F. Eckert, A. Klamt, AIChE Journal 48 ( 2002) 369-385.

[17] A. Klamt, COSMO-RS From Quantum Chemistry to Fluid Phase Thermodynamics and Drug Design, Elsevier, Amsterdam, 2005.

[18] A. Klamt, G. Schüürmann, J. Chem. Soc. Perkin Trans. 2 (1993) 799-805.

[19] A. Ben Naim, Solvation Thermodynamics, Plenum Press, New York 1987.

[20] A.D. Becke, Phys. Rev. A 38 (1988) 3098-3100.

[21] S.H. Vosko, L Wilk, M. Nussair, Can. J. Phys. 58 (1980) 1200-1211.

[22] J.P. Perdew, Phys. Rev. B 33 (1986) 8822-8824.

[23] A. Schäfer, C. Huber, R. Ahlrichs, J. Chem. Phys. 100 (1994) 5829-5835.

[24] K. Eichkorn, F. Weigend, O. Treutler, R. Ahlrichs Theor. Chem. Acc. 97 (1997) 119 124.

[25] TURBOMOLE V6.1 2009, a development of University of Karlsruhe and Forschungszentrum Karlsruhe GmbH, 1989-2007, $25 \mathrm{GmbH}$, since 2007; available from http://www.turbomole.com.

[26] F. Eckert and A. Klamt, COSMOtherm, Version C2.1, Release 01.08; COSMOlogic GmbH \& Co. KG, Leverkusen, Germany, 2006. 
[27] M. Diedenhofen, F. Eckert, A. Klamt, J. Chem. Eng. Data 48 (2003) 475-479.

[28] C. Jork, C. Kristen, D. Pieraccini, A. Stark, C. Chiappe, Y.A. Beste, W. Arlt, J. Chem. Thermodynamics 37 (2005) 537-558.

[29] T. Banerjee, R.K. Sahoo, S.S. Rath, R. Kumar, A. Khanna, Ind. Eng. Chem. Res. 46 (2007) 1292-1304.

[30] T. Banerjee, K.K. Verma, A. Khanna, AIChE Journal 54 (2008) 1874-1885.

[31] C.-T. Wu, K.N. Marsh, A.V. Deev, J.A. Boxall, J. Chem. Eng. Data 48 (2003), 486-491.

[32] M.G. Freire, L.M.N.B.F. Santos, I.M. Marrucho, J.A.P. Coutinho, Fluid Phase Equilibria 255 (2007) 167-178.

[33] M.G. Freire, S.P.M. Ventura, L.M.N.B.F. Santos, I.M. Marrucho, J.A.P. Coutinho, Fluid Phase Equilibria, 268 (2008) 74-84.

[34] Z. Lei, W. Arlt, P. Wasserscheid, Fluid Phase Equilibria 241 (2006) 290-299.

[35] M. Thormann, A. Klamt, M. Hornig, M. Almstetter, J. Chem. Inf. Model. 46 (2006) 1040 $-1053$.

[36] J. Palomar, J.S. Torrecilla, V.R. Ferro, F. Rodriguez, Ind. Eng. Chem. Res. 47 (2008) 4523-4532.

[37] J. Palomar, V.R. Ferro, J.S. Torrecilla, F. Rodriguez, Ind. Eng. Chem. Res. 46 (2007) 6041-6048.

[38] M. Diedenhofen, A. Klamt, K. Marsh, A. Schäfer, Phys. Chem. Chem. Phys. 9 (2007) 4653-4656.

[39] T. Banerjee, A. Khanna, J. Chem. Eng. Data 51 (2006) 2170-2177.

[40] X. Zhang, Z. Liu, W. Wang, AIChE Journal 54 (2008) 2717-2728.

[41] A. Maiti, Chem. Sus. Chem. 2 (2009) 628-631.

[42] N. Ab Manan, C. Hardacre, J. Jacquemin, D.W. Rooney, T.G.A. Youngs, J. Chem. Eng. Data 54 (2009) 2005-2022.

[43] K.N. Marsh, J.A. Boxall, R. Lichtenthaler, Fluid Phase Equilibria 219 (2004) 93-98.

[44] K. Sahandzhieva, D. Tuma, S. Breyer, Á. Pérez-Salado Kamps, G. Maurer, J. Chem. Eng. Data 51 (2006) 1516-1525.

[45] U. Domańska, A. Pobudkowska, F. Eckert, J. Chem. Thermodynamics 38 (2006) 685695.

[46] U. Domańska, A. Pobudkowska, F. Eckert, Green Chem.8 (2006) 1-10.

[47] M.G. Freire, C.M.S.S. Neves, P.J. Carvalho, R.L. Gardas, A.N. Fernandes, I.M.

Marrucho, L.M.N.B.F. Santos, J.A.P. Coutinho, J. Phys. Chem. B 111 (2007) 13082-13089. 
[48] M.G. Freire, P.J. Carvalho, R.L. Gardas, L.M.N.B.F. Santos, I.M. Marrucho, J.A.P. Coutinho, J. Chem. Eng. Data 53 (2008) 2378-2382.

[49] A. Arce, M.J. Earle, S.P. Katdare, H. Rodríguez, K.R. Seddon Fluid Phase Equilibira 261 (2007) 427-433.

[50] T. Banerjee, M. K. Singh, A. Khanna, Ind. Eng. Chem. Res. 45 (2006) 3207-3219.

[51] M.B. Shiflett, A. Yokozeki, AIChE Journal 52 (2006) 1205-1219.

[52] A. Yokozeki, M.B. Shiflett, Ind. Eng. Chem. Res. 46 (2007) 1605-1610.

[53] J.W. Kang, K.-P. Yoo, H.Y. Kim, H. Lee, D.R. Yang, C.S. Lee, Korea Thermo physical Properties Databank (KDB), Department of Chemical Engineering, Korea University, Seoul, Korea, 2000.

[54] Z. Lei, B. Chen, C. Li, Chem. Eng. Science 62 (2007) 3940-3950.

[55] A.A.P. Kumar, T. Banerjee, Fluid Phase Equilibria 278 (2009) 1-8.

[56] Z. Guo, B. Chen, R. López Murillo, T. Tan, X. Xu, Org. Biomol. Chem. 4 (2006) $2772-$ 2776.

[57] A.Maiti, P.F. Pagoria, A.E. Gash, T.Y. Han, C.A. Orme, R.H. Gee, L.E. Fried, Phys. Chem. Phys. 10 (2008) 5050-5056.

[58] A. Heintz, J.K. Lehmann, C. Wertz, J. Chem. Eng. Data 48(3) (2003) 472-474. 
Figure captions

Meta file approach

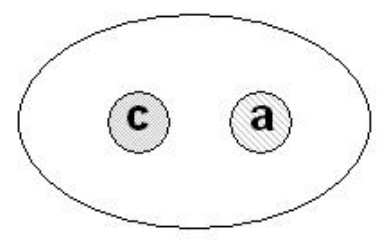

The IL is treated as one compound. (sum of the $\sigma$-profiles, areas and volumes of the ions)
Ion pair

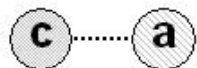

The ion pair is calculated on the COSMO level

Fig. 1. Schematic description of the possible representation of an 1:1 IL in COSMO-RS.

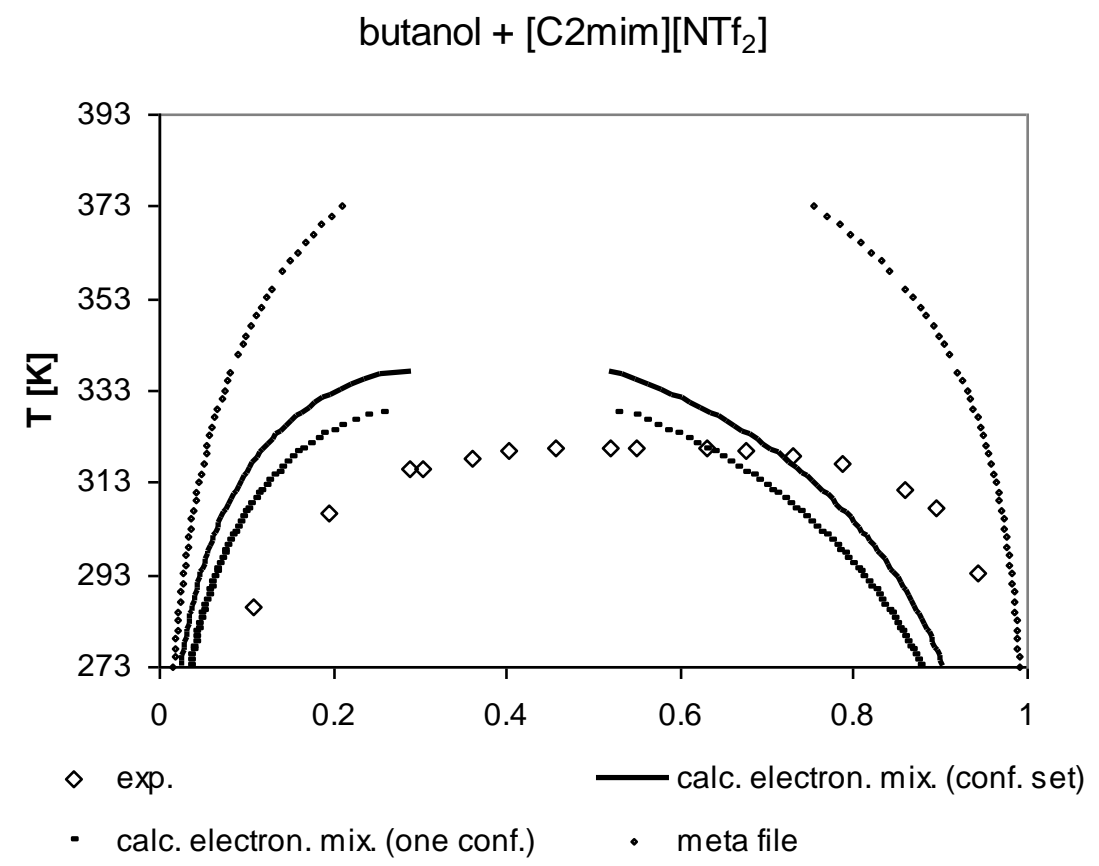

Fig. 2. Solubility (in mass fraction $w$ ) of 1-butanol in $\left[\mathrm{C}_{2} \mathrm{mim}\right]\left[\mathrm{NTf}_{2}\right]$ calculated using the electroneutral mixture with one conformer, the electroneutral mixture with a set of conformers and the meta-file approach. Experimental values taken from ref. [58]. 


\section{1-butanol}
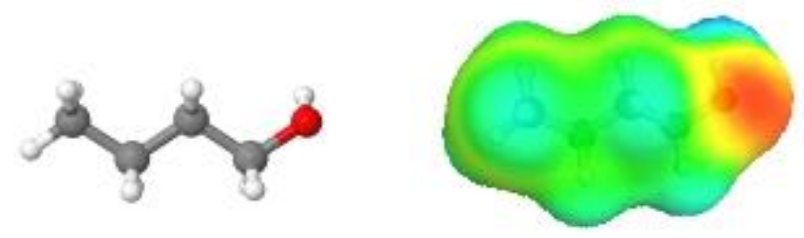

$\left[\mathrm{C}_{2} \mathrm{mim}\right]$
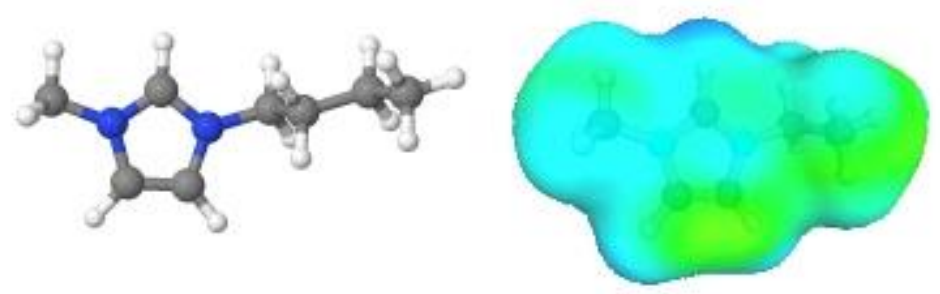

$\left[\mathrm{NTf}_{2}\right]$
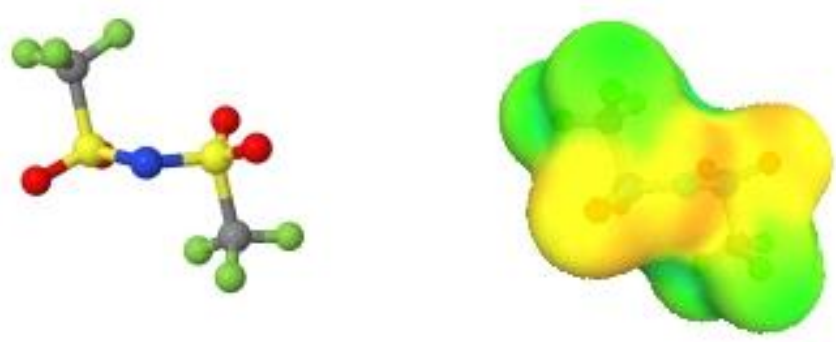

Fig. 3. Screening charge density $\sigma$ and structures of the minimum conformers of 1-butanol, $\left[\mathrm{C}_{2} \mathrm{mim}\right]$ and $\left[\mathrm{NTf}_{2}\right]$. 


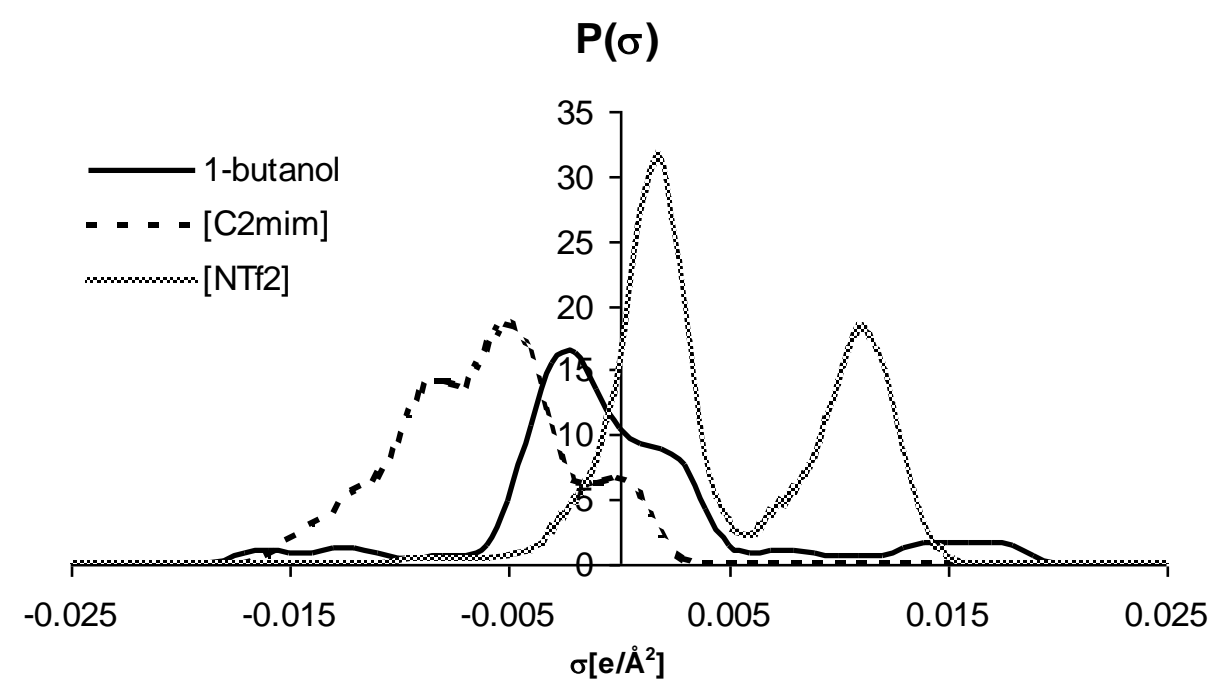

Fig. 4. $\sigma$-profiles of the minimum conformers of 1-butanol, $\left[\mathrm{C}_{2} \mathrm{mim}\right]$ and $\left[\mathrm{NTf}_{2}\right]$. Please note that due to the definition as conductor screening charges electrostatically positive parts of the molecules have negative $\sigma$ and vice versa. 


$$
[\mathrm{X}]\left[\mathrm{NTf}_{2}\right]+\left[\mathrm{P}_{6,6,6,14}\right]\left[\mathrm{NTf}_{2}\right]
$$

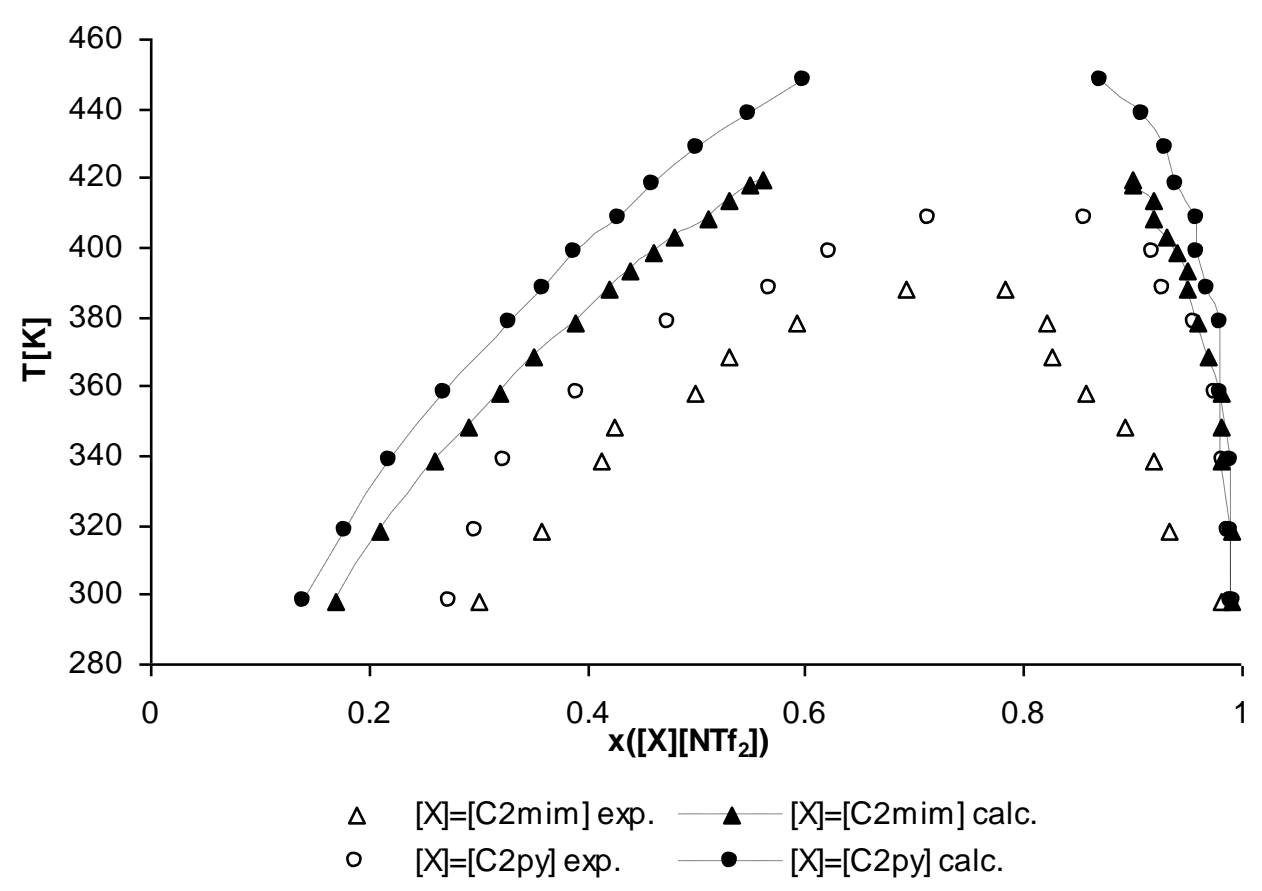

Fig. 5. Solubility (in mole fraction $x$ ) of $\left[\mathrm{C}_{2} \mathrm{mim}\right]\left[\mathrm{NTf}_{2}\right]$ and $\left[\mathrm{C}_{2} \mathrm{py}\right]\left[\mathrm{NTf}_{2}\right]$ in $\left[\mathrm{P}_{6,6,6,14}\right]\left[\mathrm{NTf}_{2}\right]$ calculated using the electroneutral mixture approach. Experimental data taken from ref. [49].

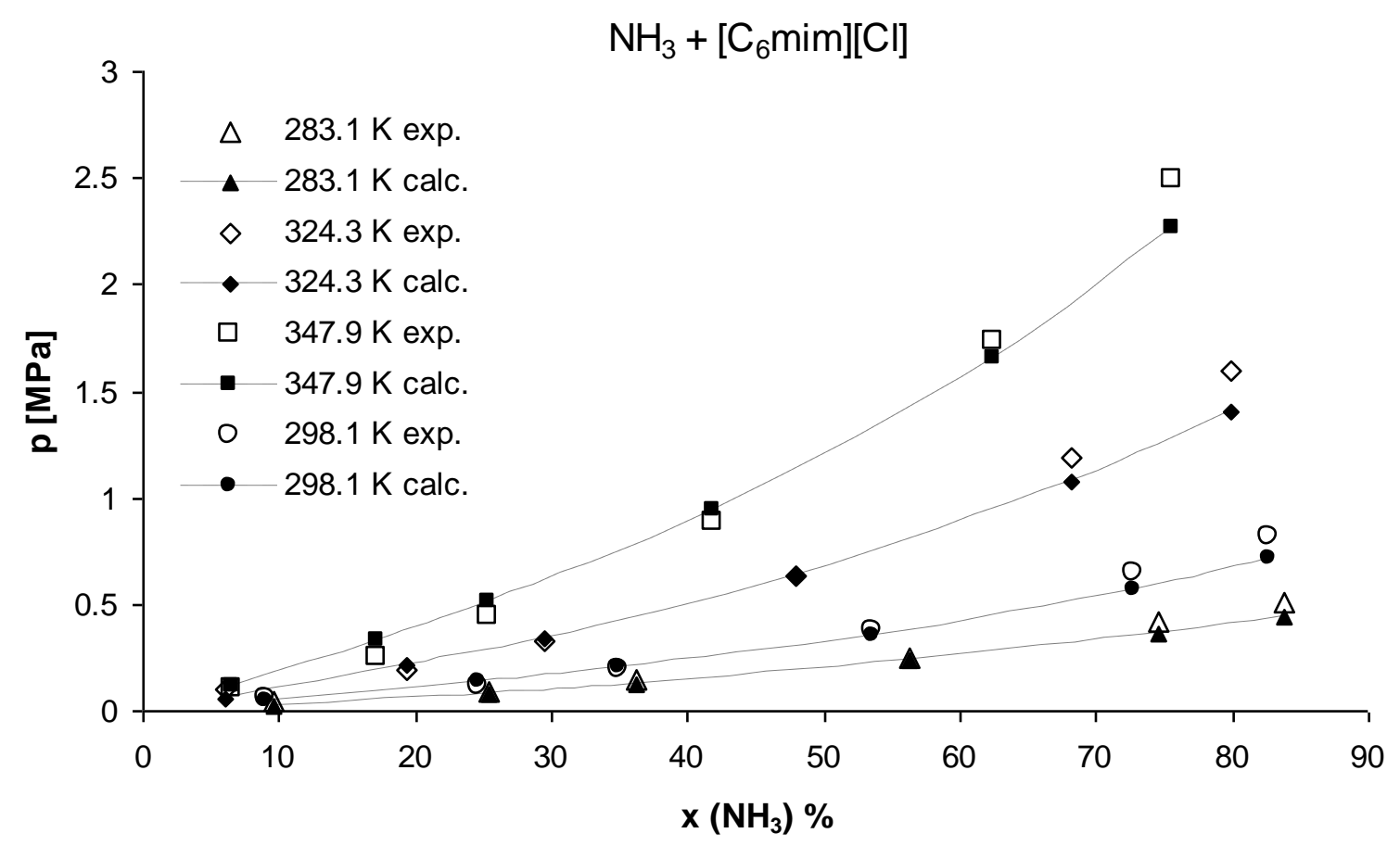


Fig. 6. $\mathrm{pT} x$ phase diagram of the $\mathrm{NH} 3+\left[\mathrm{C}_{6} \mathrm{mim}\right][\mathrm{Cl}]$. Experimental data taken from ref. [52].

\section{$1 /\left[\mathrm{C}_{4} \mathrm{mim}\right]\left[\mathrm{PF}_{6}\right]$ at $283.15 \mathrm{~K}$}

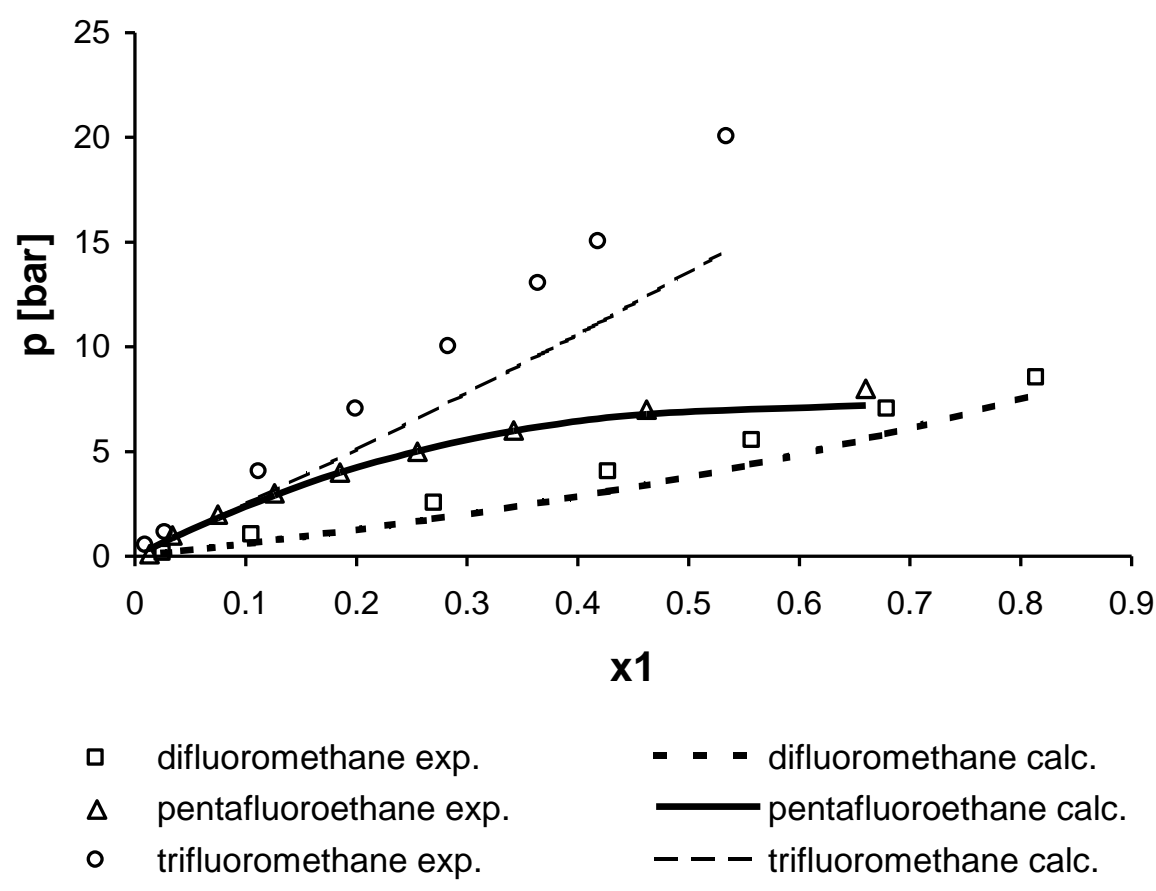

Fig 7. pTx phase diagram of fluoroalkanes $+\left[\mathrm{C}_{6} \mathrm{mim}\right]\left[\mathrm{PF}_{6}\right]$ at $283.15 \mathrm{~K}$. Experimental data taken from ref. [51]. 
$1 /\left[\mathrm{C}_{4} \operatorname{mim}\right]\left[\mathrm{PF}_{6}\right]$ at $323.15 \mathrm{~K}$

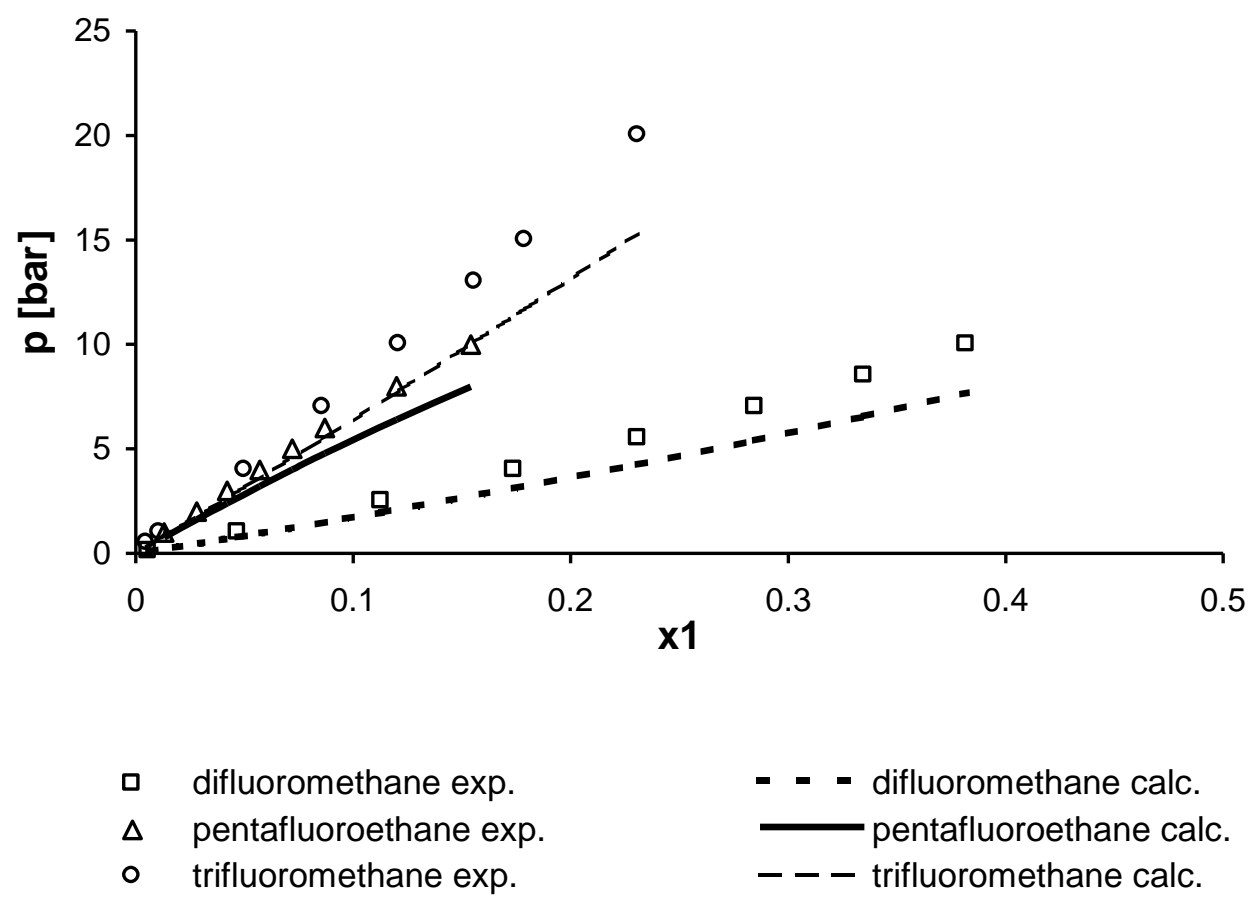

Fig 8. $\mathrm{pT} x$ phase diagram of fluoroalkanes $+\left[\mathrm{C}_{6} \mathrm{mim}\right]\left[\mathrm{PF}_{6}\right]$ at $323.15 \mathrm{~K}$. Experimental data taken from ref. [51]. 